\title{
THE FICTION OF A FACTUAL APPROACH TO DECISION-MAKING
}

\author{
Sibs von Solms \\ Faculty of Commerce, Administration and Law \\ Department of Business Management \\ University of Zululand \\ Richards Bay, South Africa \\ Email: sibsvonsolms@gmail.com
}

\begin{abstract}
The philosophy of the ISO9001:2008 Management System Standard is based on 8 Quality Principles of which the seventh is Factual Approach to Decision-Making. This principle is introduced and the rationale behind and reasons for its inclusion discussed. However, a paucity of critical discussions of this and other quality principles is evident and this paper attempts to point out some important aspects of this principle that requires critical re-evaluation to ensure its continued relevance to Quality Systems based on the ISO9001:2008 approach. The dichotomies Rational-Intuitive, Objective-Subjective and Quantitative-Qualitative are used to highlight areas where a too narrow application of this principle can undermine its value in Quality Systems performance. The AHP/ANP is suggested as providing the necessary structure to enhance complex decision-making in TQM and similar Quality Management regimes.
\end{abstract}

Keywords: Analytical Hierarchy Process (AHP); Factual Approach to Decision-Making; Interpretivist Paradigm; Intuitive Thinking; ISO9001:2008 Management System Standard; Multi-Criteria DecisionMaking; Positivist Paradigm; Qualitative Aspects; Quantitative Aspects; Rational Thinking; Total Quality Management.

\section{Factual Decision-Making a Feature of ISO9000}

According to the ISO9000:2005 standard [SANS, 2005], eight quality management principles have been identified that can be used by top management in order to lead the organization towards improved performance. These principles are; (i) Customer focus; (ii) Leadership; (iii) Involvement of people; (iv) Process approach; (v) System approach to management; (vi) Continual improvement; (vii) Factual approach to decision making and (viii) Mutually beneficial supplier relationships. These eight quality management principles form the basis for the quality management system standards within the ISO 9000 family. The ISO9004:2009 Standard [SANS, 2009] expands on this and says that Principle 7 Factual Approach to Decision Making - implies that effective decisions are based on the analysis of data and information. This has some key benefits: (i) Informed decisions; (ii) An increased ability to demonstrate the effectiveness of past decisions through reference to factual records; (iii) The increased ability to review, challenge and change opinions and decisions and (iv) Applying the principle of factual approach to decision making typically leads to: Ensuring that data and information are sufficiently accurate and reliable; Making data accessible to those who need it; Analysing data and information using valid methods and making decisions and taking action based on factual analysis, balanced with experience and intuition. The factual approach to decision-making forms the basis of several QMS requirements as detailed in ISO9001:2008 [SANS, 2008]. The most obvious is Clause 8: Measurement, Analysis and Improvement but it clearly also impacts on Clause 7.5.2 regarding the Validation of Production Processes and Service Provision which are the processes supplying the facts on which decisions are to be based and on Clause 7.6 on Controlling of Monitoring and Measuring Devices as this impacts on the validity of the facts produced. 


\section{Factual Decision-Making a Feature of TQM}

Another popular approach in the world-wide quality movement is that of Total Quality Management (TQM). TQM is an integrative philosophy of management for continually improving the quality of products and processes often linked to the seminal work of W Edwards Deming [Besterfield et al, 2003]. TQM functions on the premise that the quality of products and processes is the responsibility of everyone who is involved with the creation or consumption of the products or services offered by an organization. In other words, TQM capitalizes on the involvement of management, workforce, suppliers, and even customers, in order to meet or exceed customer expectations. Jablonski [1994] identifies three characteristics necessary for TQM to succeed within an organization: (i) Participative Management; (ii) Continuous Process Improvement; and (iii) The Utilization of Teams. He also identifies six attributes of successful TQM programs: (i) Customer Focus; (ii) Process Focus; (iii) Prevention versus Inspection; (iv) Employee Empowerment and Compensation; (v) Fact-Based Decision-Making and (vi) Receptiveness to feedback. Similar lists of core principles and elements of TQM, including the factual basis for decision-making, are also found in [Besterfield et al, 2003; Oakland, 2003; Anvari et al, 2011]. Detert et al [2000] say that TQM embraces an approach to truth and rationality that is based on the scientific method and the use of data for decision-making; that this value is typically called 'management by fact'; it is a central value of TQM and it is essential because all systems functioning on cause and effect exhibit relationships that are too complex to be evident without such data collection and analysis. Empirical evidence seems to indicate that processes, based on fact and systematic analysis, are critically important for TQM implementation [Baidoun, 2003; Fotopoulos \& Psomas, 2009].

\section{The Need for a Critical Review}

Black \& Porter [1996] argue that current concepts in the field of TQM are largely based upon case studies, anecdotal evidence and the prescriptions of leading 'gurus'. Consequently, there is little consensus on which factors are critical to the success of the approach and, hence, on how to evaluate the success of TQM implementations. There is also the tendency of relying on catch-phrases to promote TQM rather than sound theoretical evaluations [Wilson \& Durant, 1994]. These phrases often seem common sense, even bordering on truisms. Dean \& Bowen [1994], for example, call 'decision-making based on fact' a mantra of TQM and argue that an uncritical application of such exhortations can limit the value they are meant to convey. Welcomer et al [2001] say that there is a widespread assumption that science, reason and rationality necessarily are the bases for good decision-making, but indicate that this is not always the case and that the relative merits of rationality vs emotion require research. TQM proponents, in contrast to Management Science's contingency based explanations, frequently present TQM in terms of universalistic prescriptions but this practice is identified as a reason for several TQM failures [Dean \& Bowen, 1994; Sitkin et al, 1994; Giroux \& Landry, 1998; Soltani et al, 2008]. It is, thus, important to critically evaluate the Factual Decision-Making criterion imbedded in TQM and ISO9000 to establish whether (and when) its application will enhance or hinder quality efforts.

\section{Factual Decision-Making is Wrong}

There is a sense in which the principle of Fact-Based Decision-Making is wrong. Thinking about decision-making from a philosophic-theoretical perspective leads to the conclusion that basing decisions on facts alone is faulty. Three widely discussed dichotomies can be used to structure this philosophic-theoretical argument. 


\subsection{Dichotomy 1: Rational vs Intuitive Thinking}

Kruglanski [2001] discusses some views developed over the years regarding the relationship between emotive Motivation and rational Cognition in judgment or decision-making. The first is, what he calls, the Antagonistic Model. The basic idea of the Antagonistic Model is that motivation and cognition form separate and competing systems for judgment. It goes back to Plato and Aristotle. Aristotle, for example, proposed that the intellective or reasoning 'soul' is in frequent conflict with the passionate 'soul'. In the Aristotelian view, Reason is capable of dominating Passion and when that occurs, rationality prevails and human judgments and opinions are accurate and undistorted. The notion that motivational forces (like passion and desire) and cognitive processes (like logic or reason) are in perennial conflict has remained the accepted view over the centuries and has been a powerful force in Western culture in general [Kruglanski, 2001]. In 20th century Psychology, no lesser figure than Sigmund Freund embraced the antagonistic conception of the relation between Cognition and Motivation. Echoing Aristotle, Freud [1949] has faith in the considerable powers of rationality and the victory of Reason (Ego) over Desire (Id). In modern Social Psychology the motivation-cognition relation is depicted antagonistically as the debate between proponents of the Motivational view - that various motives, needs and desires play a significant role in judgment and attitude formation - and those who maintain that rationality is cognitive and not dependent on motivational issues. Kruglanski's [2001] second and third models are based on the fundamental assumption that all cognitive activity has some motivational base, ie that there is no 'pure' intellectualizing without some motivational underpinnings. The main difference is that the one, called the Segregationist model, postulates two qualitatively different processes to reach a decision dependent on the level of motivation involved. In its simplest form, the segregated model posits that the stronger the individuals' involvement in a topic the more they will process issue-relevant contents extensively and systematically, and the less their involvement the more they will briefly process heuristic contents. The other, Kruglanski's [1989, 2001] own Lay Epistemic Theory (LET) model, postulates a unitary process in which cognition, goal attainment and epistemic motivation play different but unified roles affecting the extent and direction of the cognitive activity so as to produce a desired epistemic end state [Kruglanski et al, 2010].

Kruglanski's [2001] conclusion is that the empirical evidence has shown that an approach positing rational cognition as, not only separate from, but also superior to emotive motivation as elements in judgment processes is faulty and that the rational-factual co-exists with the preferential-motivational in all decision-making processes (cf [Kunda, 2000; Kruglanski et al, 2010]. Kahneman [2003] summarizes the work done in conjunction with Amos Tversky (eg [Tversky \& Kahneman, 1974]) and more recent developments (eg [Kahneman \& Frederick, 2002]). Kahneman [2003] shows that this research programme indicates that two identifiable systems of judgment exist; System 1 where operations are intuitive, fast, automatic, effortless and associative, while System 2 operations are deliberative, slower, serial and effortful. He concludes that most judgments are based on intuitions formed in System 1 sometimes modified by deliberations during System 2 - a conclusion similar to that in [Kruglanski, 2001].

\subsection{Dichotomy 2: Objective vs Subjective Thinking}

The impact that the principle of Factual Decision-Making is meant to produce in TQM/ISO9000 systems is a move away from Subjective to Objective decision-making, with the implicit justification that the latter is better [Dean \& Bowen, 1994; Hoyle, 2006]. Here we enter the long and complex debate in Epistemology regarding truth and knowledge. Making good decisions relies on knowledge which in turn relies on truth as truth is supposedly an essential characteristic of knowledge as opposed to mere belief. From a Realist perspective the world exists independent of any human interpretation. The Realist notion of truth is seen as correspondence between statements or beliefs (facts) about this world and the way the objectively existing world actually is. The Correspondence View is the main and most obvious view of truth in Epistemology [Mingers, 2008]. However, this view has come under severe attack from several sides. The one of interest here is that of Constructivism (or Interpretivism). From a Constructivist point of view of truth, reality is that which results from peoples' subjective 
interpretations of the world [Mingers, 2008]. Gioia [2003], for example, accepts that things do exist and that there are indeed 'facts', but that these in themselves are uninteresting and irrelevant until they become part of the social world through interpretation, discussion and debate. Rorty [1982] holds a similar view that although reality exists objectively, descriptions of and beliefs about the world can only exist in the subjective human interpretations of that reality.

The argument is often made that scientific approaches should be based on factual rather than ethical or evaluative statements but this approach is seen as limiting, even harmful [Ruckelshaus, 1985; Montague, 2004]. Scientists are learning to take seriously processes of cognition that deviate from the norms of the classical scientific method. Purposeful (human) systems are not value-free but value-laden [Jackson, 2003], choosing from available alternatives on the basis of normative statements such as 'should' or 'ought'. It is clear that there is a place for appreciating ethics and subjective values in decision-making and for methodologies designed to deal with these issues [Saaty, 2010].

\subsection{Dichotomy 3: Quantitative vs Qualitative Approaches}

Two main approaches to data and measurement is often juxtaposed, hard (scientific) quantitative against soft qualitative data. If we are to base all decisions on facts, the question arises whether quantitative data represents factual information better than qualitative data would.

The view that only quantitatively measured data is of real scientific value is called the quantitative imperative and it leads to the practice of wanting to measure everything [Barrett, 2003; Kvale, 2008]. This practice is identified by Michell [2003, 2008] as a political campaign protecting a scientistic image of the Social Sciences, specifically Psychology, and packaging Psychological tests as methods of scientific measurement, a campaign necessary leading to an egregious, potentially self-perpetuating form of methodological error.

This leads one into the thorny debate regarding measurement theories. Two main approaches to defining measurement are the Traditional and the Representational Measurement Theories [Acton, 2003]. The Traditional Measurement Theory (TMT) has been widely accepted in the physical sciences since its development by Hölder - who synthesized the approaches of Euclid, Newton and Dedekind. The TMT entertains an empiricist account of number [Acton, 2003]. Michell [1999] believes that the attitude promising the most coherent defense of science is that of Empirical Realism. Within this philosophical perspective measurement becomes the exercise of establishing a correspondence between quantitative variables in the world and numerical instruments [Michell, 1999, 2008; Acton, 2003]. According to Michell [1999] a quantitative attribute has a distinctive kind of internal structure, viz quantitative structure, and only such attributes can be expressed as real numbers and are in principle measurable. Michell [2008] is adamant that measurement is to be used in this way only. Russell criticized The TMT at the beginning of the twentieth century and developed the Representational Measurement Theory (RMT) [Acton, 2003]. Within the RTM, measurement of attributes of a set of things is the process of assigning numbers (or other symbols) to the things in such a way that relationships of the numbers or symbols reflect relationships of the attribute being measured. The RMT, hence, allows the measurement of variables which the TMT will classify as non-quantitative, for example the measurement of IQ. Michell [1999], in an emotive argument against RMT, argues that this view is mistaken as it is based on several erroneous philosophical foundations; Pythagoreanism and Practicalism inter alia. For the likes of Michell [1999, 2008] the value of scientific endeavours in general and measurement operations in particular lies in Realism, in measuring real entities that can be empirically and objectively shown to have quantitative structure.

While science and reason improve the understanding of human existence and the human environment, the facts and understanding obtained through science and reason is fundamentally related to human values, needs and to the judgments that serve these values and needs [Saaty, 2001]. The view excluding the myriad of intangibles and qualitative human nature from decision-making, by insisting that only tangible and concrete objects, captured through science, can be measured or included in decision- 
making, must be rejected. The world is replete with intangibles, and insistence on measuring only tangibles excludes many of the goals and criteria important to political, social and environmental problems. This makes the problem of measuring intangibles an important concern facing anyone who wants to grapple successfully with decision-making [Saaty, 2001, 2010]. It is clear that not only must the critique of the TMT aimed at RMT be rejected but, more importantly, the insistence of the TMT proponents that only tangibles (quantitative variables) can be measured must be rejected because it excludes immediately the possibility of any real world decision-making in which intangibles always play an important role [Saaty, 2001, 2010, 2013].

\section{Factual Decision-Making is Limiting}

The discussion above may create the impression that Fact-Based Decision-Making has no role to play in organizational decision-making. This would fly in the face of common sense and many of the examples found in the Quality Management literature. From a practical rather than a conceptual point of view a critical evaluation leads to a different conclusion: Fact-Based Decision-Making may not be wrong but is better characterize as limited to only a small set of real important organizational decision-making situations.

\subsection{Routine vs Non-Routine Decisions}

Sayers [2008] points out that it is a commonly-held but incorrect view that Deming [1986, 1993] was a firm exponent of the philosophy 'you can't manage what you can't measure'. It is worth noting that number five on Deming's [1993] list of 'Seven Deadly Diseases of Western Management' is: 'Running a company with visible figures alone'. It is Deming's [1986] assertion that a lot of important management information is either unknown or even unknowable, and Sayers [2008] argues that we can waste a lot of time chasing the unattainable goal of a 100\% Factual Approach to Decision Making. This has to be put in proper context, however, as Deming did support the practice of data collection and analysis in general, especially where it had the practical outcome of reducing the risk in the decision making process. Deming is one of the early and strong proponents of Statistical Process Control (SPC) to achieve, maintain and improve quality [Wheeler \& Chambers, 1992; Kennedy, 2002] and it cannot be said that he shuns the use of quantitative data as a basis for managerial decisions; on the contrary, he was an active and lifelong promoter of this idea, but with the proviso that it should be used correctly [Giroux \& Landry, 1998]. Deming [1986] is, however, adamant that even though the most important figures that one needs for management are unknown or unknowable, successful management must nevertheless take account of them. There are at least three reasons for information to be unknown or unknowable. First, managerial decision-making often involve risk and is future-orientated making the evaluation as to whether such decisions are correct not knowable a priori [Sayers, 2008]. Second, managerial problems are mostly complex with several interrelated and sometimes even conflicting issues. The third has to do with the difference between natural and social systems. Physical systems are governed by a limited number of deterministic laws. Social systems, however, are influenced by innumerable variables and, because of the self-consciousness and free will exhibited by humans, the behaviour of social systems cannot be explained in deterministic terms. Humans think and learn, act according to their own purposes and are capable of reacting against and disproving any law that is said to apply to their behaviour. Jackson [2003] points out that during the 1970s and 1980s, Operational Research (OR) and Management Science (MS) were obsessed with perfecting mathematical solutions to a small range of tactical problems and the methodologies and tools then available could only be successful if used on relatively simple and routine problems. He says, however, that most of the pressing problems managers face are ill-structured problem situations made up of highly interdependent problems; non-routine, strategic in nature and set in social systems. Hence, many real quality problems are complex and require problem solving and decision-making processes that allow the identification and evaluation of multiple criteria and alternatives [Liang \& Zhang, 2010].

The point then is not that data- or fact-based decision-making is necessarily wrong but rather that the type of decisions amenable to this type of treatment is limited to day-to-day shop floor decisions for 
which quantitative data is available, means and standard deviations can be determined and control limits set. Any problem situation that involves multiple criteria and alternatives, particularly if some of the criteria are intangible aspects, may be solved incorrectly if tools that cannot adequately handle multiple criteria and integrate quantitative and qualitative data are applied.

\subsection{Limiting Decisions to Quality of Products}

von Solms [2002] claims that the increasing competitive impact of addressing Occupational Health, Safety and Environmental concerns, makes SHE management a new priority of senior management. The pressure from the green lobby, legal requirements and communities as well as the responsibility for a safe and healthy environment for its employees makes sound OHS and Environmental management a problem of vital importance for any business over and above the emphasis on Quality and Efficiency [Larson et al, 2000]. ISO 14001, as a formal EMS Standard, requires (inter alia) the identification and assessment of environmental aspects and their related impacts to determine the significance of the latter, making the assessment of Environmental Impacts a very important aspect of a company's environmental efforts. The same situation is found in OHSAS 18001, as a formal OHS Management System Standard, requiring the identification and assessment of health and safety risks. Unanimity does not exist as to the best way to perform this type of assessment [Cascio, 1996; Montague, 2004]. The issue relevant here is that it involves a decision-making process and, the fact that some of the issues to be considered, in determining the final significance, are subjective and rely on ethic and value perceptions seems to require a move away from the rational-quantitative approach to a more inclusive one. The same arguments abound in the Risk Assessment literature [Kadvany, 1995; Montague, 2004] and several of the risk policy establishments are now emphasising the central importance of intrinsically subjective value judgements in risk analysis [Stirling, 1998]. There has been much debate about the appropriate tools for the improvement of organizational environmental performance. However, there is now a need to go further than simply addressing the environmental performance of companies by focusing on the broader principle of Sustainable Development (SD) - seeking solutions in which the current generations can meet their needs without compromising the ability of future generations to meet their own. No longer can social, economic, environmental and development be seen as separate issues, their interdependence has become clearly established [von Solms, 2001].

The only way to ensure ourselves a safer, more prosperous future is to deal with environment and development issues together, in a balanced manner [Larson et al, 2000]. We must fulfil human needs, improve living standards for all and better protect and manage ecosystems in a global partnership of Sustainable Development. Hence, organizational decision-making has to be expanded to incorporate and balance - (economic) quality with environmental, social, safety and health issues [Wood, 1997; Petkov et al, 1998; von Solms, 1998, 2001, 2002].

\section{Conclusion}

If decision-making is embedded in a Hard Systems Paradigm (HSP) [Jackson, 2003] with a Realist Ontology, Positivist Epistemology and Naturalistic Sociology, fact-based decision-making follows naturally. But this was shown to be wrong as it cannot adequately accommodate subjective meanings, preferences and values required for decision-making that can address the real important human issues facing mankind in the $21^{\text {st }}$ century. Fact-based decision-making within the HSP is, from a practical point of view, limited as it excludes adequate addressing of strategic, human resource, environmental, social, health and safety issues. Addressing all these issues in a balanced manner requires two things. First, the HSP must be replaced by a Pluralistic Paradigm within which both hard (quantitative) as well as soft (qualitative) assumptions are integrated [Petkov et al, 1998; Jackson, 2003]. Second, real integrated decision-making is by nature multi-criteria decision-making and this highlights the need for decision-making methodologies that can adequately cater for multiple criteria trade-offs; the integration of quantitative as well as qualitative variables within a single structure; meet the requirements of 
diverse customers [Wood, 1997] and encompass the numerous definitions of quality and TQM [Giroux \& Landry, 1998; Giroux, 2006].

The Analytical Hierarchy Process (AHP) is suggested as meeting all of these requirements because it: (i) Fits a Pluralistic Paradigm including both Hard and Soft systems perspectives [Petkov \& MihovaPetkova, 1997; Petkov et al, 1998; von Solms, 1998]; (ii) Allows multiple viewpoints of diverse stakeholders [von Solms, 1998; Saaty \& Peniwati, 2008]; (iii) Allows multiple criteria and alternatives facilitating complex multi-facetted decisions to integrate Quality, Environmental, Health and Safety and Social issues [von Solms, 1998, 2001, 2002; Saaty, 2001, 2010; Schmoldt et al, 2001]; (iv) Integrates Tangible (Quantitative) and Intangible (Qualitative) elements [Saaty, 2010, 2013]. The validity of the AHP/ANP in subjectivist, multi-stakeholder situations is demonstrated in [von Solms, 2011], over and above its validity in more traditional hard systems contexts, the latter demonstrated in [Whitaker, 2004].

\section{REFERENCES}

Acton, GS; (2003); What is Good About Rasch Measurement?; Rasch Measurement Transactions 16/4; 902-903

Anvari, A; Ismail, Y \& Hojjati, SMH; (2011); A Study on Total Quality Management and Lean Manufacturing: Through Lean Thinking Approach; World Applied Sciences Journal 12/9; 15851596

Baidoun, S; (2003); An Empirical Study of Critical Factors of TQM in Palestinian Organizations; Logistics Information Management 16/2; 156-171

Barrett, PT; (2003); Beyond Psychometrics: Measurement Non-Quantitative Structure and Applied Numerics; Journal of Managerial Psychology 18/5; 421-439

Besterfield, DH; Besterfield-Michna, C; Besterfield, GH \& Besterfield-Sacre, M; (2003); Total Quality Management; $3^{\text {rd }}$ Edition; Prentice Hall; Upper Saddle River, NJ

Black, SA \& Porter, LJ; (1996); Identification of the Critical Factors of TQM; Decision Sciences 27/1; $1-21$

Cascio, J; (1996); The ISO 14000 Handbook; ASQC Quality Press; Milwaukee, WI

Dean, JW \& Bowen, DE; (1994); Management Theory and Total Quality: Improving Research and Practice Through Theory Development; Academy of Management Review 19/3; 392-418

Deming, WE; (1986); Out of the Crisis; Massachusetts Institute of Technology; Cambridge, MA

Deming, WE; (1993); The New Economics: For Industry, Government, Education; Massachusetts Institute of Technology; Cambridge, MA

Detert, JR; Schroeder, RG \& Mauriel, JJ; (2000); A Framework for Linking Culture and Improvement Initiatives in Organizations; Academy of Management Review 25/4; 850-863

Fotopoulos, CB \& Psomas, EL; (2009); The Impact of 'Soft' and 'Hard' TQM Elements on Quality Management Results; International Journal of Quality \& Reliability Management 26/2; 150-163

Freud, S; (1949); The Ego and the Id; Translated by J Reviere; $4^{\text {th }}$ Edition; Hogarth Press: Institute of Psycho-Analysis; London, UK

Gioia, DA; (2003); Give It Up! Reflections on the Interpreted World (A Commentary on Meckler and Baillie); Journal of Management Inquiry 12/3; 285-292

Giroux, H; (2006); 'It Was Such a Handy Term': Management Fashions and Pragmatic Ambiguity; Journal of Management Studies 43/6; 1227-1260

Giroux, H \& Landry S; (1998); Schools of Thought In and Against Total Quality; Journal of Management Issues 10/2; 183-203

Hoyle, D; (2006); ISO9000: Quality Systems Handbook; $5^{\text {th }}$ Edition; Butterworth-Heinemann; Oxford, UK

Jablonski, JR; (1994); Implementing TQM: Competing in the Nineties Through Total Quality Management; $2^{\text {nd }}$ Edition; Technical Management Consortium, Inc; Albuquerque, NM

Jackson, MC; (2003); Systems Thinking: Creative Holism for Managers; John Wiley \& Sons; Chichester, UK

Kadvany, J; (1995); From Comparative Risk to Decision Analysis: Ranking Solutions to Multi-Value Environmental Problems; Risk 6/4; 333-358 
Kahneman, D; (2003); Maps of Bounded Rationality: A Perspective on Intuitive Judgment and Choice; Nobel Prize Lecture (8 December 2002); American Economic Review 93/5; 1449-1475

Kahneman, D \& Frederick, S; (2002); Representativeness Revisited: Attribute Substitution in Intuitive Judgment; in Gilovich, T; Griffin, D \& Kahneman, D (Eds); Heuristics and Biases; Cambridge University Press; New York, NY

Kennedy, C; (2002); Guide to the Management Gurus: The Best Guide to Business Thinkers; $4^{\text {th }}$ Edition; Random House/Business Books; London, UK

Kruglanski, AW; (1989); Lay Epistemics and Human Knowledge: Cognitive and Motivational Bases; Plenum Publishing; New York, NY

Kruglanski, AW; (2001); Motivation and Social Cognition: Enemies or a Love Story?; International Journal of Psychology \& Psychological Therapy 1/1; 35-45

Kruglanski, AW; Orehek, E; Dechesne, M \& Pierro, A; (2010); Lay Epistemic Theory: The Motivational, Cognitive and Social Aspects of Knowledge Formation; Social and Personality Psychology Compass 4/10; 939-950

Kunda, Z; (2000); The Case for Motivated Reasoning; in Higgins, ET \& Kruglanski, AW (Eds); Motivational Science: Social and Personality Perspectives; Psychology Press; New York, NY

Kvale, S; (2008); Qualitative Inquiry Between Scientistic Evidentialism, Ethical Subjectivism and the Free Market; International Review of Qualitative Research, 1/1; 5-18

Larson, AL; Teisberg, EO \& Johnson, RR; (2000); Sustainable Business: Opportunity and Value Creation; Interfaces 30/3; $1-12$

Liang, K \& Zhang, Q; (2010); Study on the Organizational Structured Problem Solving on Total Quality Management; International Journal of Business \& Management 5/10; 178-183

Michell, J; (1999); Measurement in Psychology: Critical History of a Methodological Concept; Cambridge University Press; Cambridge, UK

Michell, J; (2003); The Quantitative Imperative - Positivism, Naive Realism and the Place of Qualitative Methods in Psychology; Theory and Psychology 13/1; 5-31

Michell, J; (2008); Is Psychometrics Pathological Science?; Measurement 6/1-2; 7-24

Mingers, JC; (2008); Management Knowledge and Knowledge Management: Realism and Forms of Truth; Knowledge Management Research \& Practice 6/1; 62-76

Montague, P; (2004); Reducing the Harms Associated with Risk Assessments; Environmental Impact Assessment Review 24/7-8; 733-748

Oakland, JS; (2003); Total Quality Management: Text with Cases; $3^{\text {rd }}$ Edition; Butterworth-Heinemann; Oxford, UK

Petkov, D; McEwan, T; von Solms, SH \& Vezjak, M; (1998); Moving Towards Compliance with Standards for Environmental Protection - An Example of Mixing Approaches to 'Messy' Problems; Proceedings $14^{\text {th }}$ European Meeting on Cybernetics \& Systems Research; Vienna, Austria

Petkov, D \& Mihova-Petkova, O; (1997); The Analytic Hierarchy Process and Systems Thinking; Proceedings $13^{\text {th }}$ International MCDM Conference; Cape Town, RSA

Rorty, R; (1982); Consequences of Pragmatism: Essays 1972-1980; University of Minnesota Press; Minneapolis, $\mathrm{MN}$

Ruckelshaus, WD; (1985); Risk, Science and Democracy; Issues in Science and Technology 1/3; 19-38

Saaty, TL; (2001); Decision-Making with Dependence and Feedback: The Analytic Network Process; $2^{\text {nd }}$ Edition; RWS Publications; Pittsburgh, PA

Saaty, TL; (2010); Principia Mathematica Decernendi: Mathematical Principles of Decision-Making; RWS Publications; Pittsburgh, PA

Saaty, TL; (2013); On the Measurement of Intangibles. A Principal Eigenvector Approach to Relative Measurement Derived from Paired Comparisons; Notices of the American Mathematical Society 60/2; 192-208

Saaty, TL \& Peniwati, K; (2008); Group Decision Making: Drawing Out and Reconciling Differences; RWS Publications; Pittsburgh, PA

SANS; (2005); SANS ISO 9000:2005: Quality Management Systems - Fundamentals and Vocabulary; Edition 3; Standards South Africa; Pretoria, RSA

SANS; (2008); SANS ISO 9001:2008: Quality Management Systems - Requirements; Edition 4; Standards South Africa; Pretoria, RSA 
SANS; (2009); SANS ISO 9004:2009: Managing for the Sustained Success of an Organization - A Quality Management Approach; Edition 3; Standards South Africa; Pretoria, RSA

Sayers, S; (2008); Management Responsibility: A Deming's Eye View; Inform - IRCA E-zine; Issue 18; On-Line at http://www.irca.org/inform/issue18/ssayers.html

Schmoldt, DL; Kangas, J; Mendoza, GA \& Pesonen, M (Eds); (2001); The Analytic Hierarchy Process in Natural Resource and Environmental Decision Making; Kluwer Academic Publishers; Dordrecht, The Netherlands

Sitkin, SB; Sutcliff, KM \& Schroeder, RG; (1994); Distinguishing Control from Learning in Total Quality Management: A Contingency Perspective; Academy of Management Review 19/3; 537-564

Soltani, E; Lai, P-C; Javadeen, SRS \& Gholipour, TH; (2008); A Review of the Theory and Practice of Managing TQM: An Integrative Framework; Total Quality Management 19/5; 461-479

Stirling, A; (1998); Risk at a Turning Point?; Journal of Risk Research 1/2; 97-109.

Tversky, A \& Kahneman, D; (1974); Judgment under Uncertainty: Heuristics and Biases; Science 185/4157; 1124-1131

von Solms, SH; (1998); A Systems Approach to TQM for Integrating Quality and Environmental Management; Unpublished MCom Thesis; University of Natal, Pietermaritzburg; RSA

von Solms, SH; (2001); Adopting a Multi-Criteria Decision-Making Approach to Sustainable Development; NEMSA Conference 2001, Midrand, RSA; April

von Solms, SH; (2002); A Multi-Disciplinary Approach to SHE Risk Assessment; TAPPSA Berg Conference; Champagne Sports Resort, Winterton, RSA; March

von Solms, SH; (2011); Validity of the AHP/ANP: Comparing Apples and Oranges; International Journal of the Analytic Hierarchy Process 3/1; 2-27

Wheeler, DJ \& Chambers, DS; (1992); Understanding Statistical Process Control; SPC Press; Knoxville, TN

Wilson, LA \& Durant, RF; (1994); Evaluating TQM: The Case for a Theory Driven Approach; Public Administration Review 54/2; 137-146

Welcomer, SA; Gioia, DA \& Kilduff, M; (2001); Reason Doesn't Rule in Waste Facility Siting; Waste Age 32/4; 24-26

Whitaker, RS; (2004); Validation Examples for the Analytic Hierarchy Process and the Analytic Network Process; Proceedings $17^{\text {th }}$ International Conference on Multiple Criteria Decision Analysis; Whistler, BC, Canada; August

Wood, M; (1997); The Notion of the Customer in Total Quality Management; Total Quality Management 8/4; 181-194 